\title{
An analysis of price gouging in the US healthcare system
}

\author{
William J. Riley*1, Natasha M. Coult ${ }^{2}$, Kailey Love ${ }^{1}$ \\ ${ }^{1}$ College of Health Solutions, Arizona State University, Phoenix, United States \\ ${ }^{2}$ West Monroe Partners, Minneapolis, United States
}

Received: June 29, 2019

Accepted: September 3, 2019

Online Published: September 24, 2019

DOI: $10.5430 /$ jha.v8n6p7

URL: https://doi.org/10.5430/jha.v8n6p7

\begin{abstract}
Increasing attention has been given to price gouging by hospitals and physicians, a practice that is related to three forms of market pricing power: price setting, price negotiating, and price taking. This paper presents a discussion of healthcare pricing patterns and their relationship to charges, payments, costs, and cost shifting. Recommendations to address price gouging in a manner that is fair to all stakeholders are proposed.
\end{abstract}

Key Words: Healthcare price gouging, Price taking, Price negotiation, Price setting, Healthcare payment

\section{INTRODUCTION}

Increasing attention has been given to hospital and physician pricing practices regarding three separate but related concerns over prices charged to uninsured individuals, surprise bills for out-of-network services, and the lack of transparency concerning information about negotiated prices between providers and insurers. This paper presents: 1) a discussion of healthcare pricing behavior patterns; 2 ) an analysis of the relationships between charges, costs, and cost shifting; and 3) recommendations for policy initiatives to address healthcare price gouging.

Hospitals and their medical staff function as price setters, price negotiators, and price takers depending on the payer source. As a result, an extremely common, yet poorly understood healthcare billing practice unfairly targets uninsured and underinsured patients as well as insured patients who become subject to price-setting behavior. This practice includes surprise out-of-network medical billing, balance billing, out of network billing, and private payment by the uninsured.
When prices are set at an unfair level and patients have little ability to negotiate payment, these activities can be defined as price gouging: the practice of raising prices of services to an unfair level, typically implying exploitative practices. The consequence is growing alarm among lawmakers and other observers, as well as a poor reflection on the hospitals and physicians who participate in this practice.

Most hospital and physician prices bear little relationship to the actual cost of care and have evolved over several decades based on a widening gap from Medicare and Medicaid payment practices and concomitant shadow payments negotiated by health insurers. Consequently, the often exorbitant outof-network (OON) liabilities reflect the differential pricing power of large payers and less so a competitive and deliberate hospital pricing strategy to create value for the consumer and community. This phenomenon of some patients paying less and some more for the same care has evolved due to a multiplicity of factors associated with price negotiating, price setting, and price taking behavior and as a result, hospital

*Correspondence: William J. Riley; Email: William.J.Riley@asu.edu; Address: 550 N 3rd St, Phoenix, AZ 85004, United States. 
and physician billing departments leverage the small insurers and individuals without coverage to fill the payment gap. ${ }^{[1]}$

\section{HeAlthCARE PRICING BEHAVIOR PAT- TERNS}

Healthcare charges set by providers and payments from payers are determined by a complex set of transactions. Healthcare provider prices are based upon a single chargemaster maintained by hospitals and physicians, usually updated annually. However, these full prices are only paid by a small segment of patients. For the preponderance of patients, there are numerous contractual relationships between payers and providers regarding agreed-upon discounts from these prices. This practice results in a wide range of payments for the same service based on a variety of contractual relationships with payers. Although the chargemaster prices remain constant, the payment rates vary considerably. This range of payments extends from bad debts, which result in no payment of charges, to some payers who pay $100 \%$ of charges. Three healthcare pricing behaviors are identified in Table 1 and classify the hospital and physician as price setters, price negotiators, or price takers. Price setting behavior occurs when there is no contractual relationship and/or weak negotiating power between the provider and payer, and the price charged to the patient reverts to the price chargemaster. Price-setting is where price gouging practices occur most frequently because of the commanding market power of the provider. Price negotiator behavior occurs when the provider has an opportunity to negotiate with a payer for an agreed-upon rate. This negotiated price is based upon buyers and sellers' ability to make independent decisions and agree upon a market clearing price that is acceptable to both parties. Price taking behavior occurs when the payer establishes a payment and imposes that payment amount by regulation upon the provider. The fee schedules from Medicare and Medicaid program are the most prominent example of providers behaving as price takers. As price takers, providers have the option to accept the payment from the price setter or decline to provide care to patients with coverage from that payer. Generally, payments received from payers in the price setting category are the highest, while payments in the price taker category are the lowest.

Table 1. Healthcare pricing behavior

\begin{tabular}{lll}
\hline Price Setter & Price Negotiator & Price Taker \\
\hline Uninsured/Private Pay Out of Necessity & Commercial Insurance & Medicare \\
Out-of-Network/Surprise Medical Billing & Third Party Administrators (TPA) & Medicaid \\
Balance Billing & Pre-Arranged Private Pay & State \& Local Safety Net Sources \\
\hline
\end{tabular}

Table 2 shows the relationship between the pricing behavior classification and the amount of payment to the provider. Price setting behavior is typically related to the highest payment amounts to the provider, while bad debt and uncompensated care are related to the lowest provider payment amounts. Table 2 also shows that pricing behavior is re- lated to the provider operating margin. Patients and payers subjected to provider price-setting behavior typically pay a greater amount than when providers are price negotiators or price takers. Payers without reasonable contractual arrangements with providers are often subjected to price setting behavior known as "price gouging".

Table 2. Pricing behavior relationship to payment received

\begin{tabular}{lll}
\hline Provider Pricing Behavioral Hierarchy & Payment Amount & Contribution to Operating Margin \\
\hline Price Setter & Highest & Most \\
Price Negotiator & High & \\
Price Taker & Low & Least \\
Bad Debt/Uncompensated Care & Lowest & \\
\hline
\end{tabular}

Price gouging is a well-known term in other industries and defined as the practice of raising prices on certain types of services to an unfair level, especially during a state of emergency and typically implies unethical and exploitative practices. Price gouging is often practiced ${ }^{[2]}$ by retailers when an area is faced with a natural disaster, and many states have laws against these practices. In the healthcare industry, activities resembling price gouging are apparent in price setting behavior when chargemaster prices are used for patients who pay entirely for their own care (private pay) and 
insured patients who receive out-of-network (OON) services, surprise medical bills, and balance bills. While chargemaster prices are not increased for individual patients due to legal restrictions, the required payment amount has the appearance of price gouging because the patient has no ability to secure meaningful reductions from full price, unlike patients who have the protection of a contract between provider and payer. In contrast to price gouging in other industries, healthcare providers presumably do not set their chargemaster prices with unethical and exploitative intent, though the impact can be similar.

Critics have characterized surprise medical billing, a key element of price-setting behavior, as the healthcare equivalent of a carjacking ${ }^{[3]}$ and these anti-competitive practices have been described as a pernicious ${ }^{[4]}$ protection racket ${ }^{[3]}$ akin to stealing. This price-setting capability reflects those instances when providers charge high prices not when they need to, but when they can. ${ }^{[4]}$ Price-setting behavior, wherein providers set a non-negotiable and unaffordable price for their services and require full payment from vulnerable patients, contributes, in part, to the conclusion that healthcare is America's largest and most dysfunctional industry. ${ }^{[5]}$

Patients who encounter surprise OON medical billing, balance billing, OON billing, and private payment must pay the prices set by the provider and have limited to nonexistent ne- gotiation power. This behavior is most egregious when compared to the negotiation power of commercial insurance plans and regulatory power of Medicare and Medicaid. Patients subjected to price gouging must pay a far higher amount than patients who are insured by price negotiators and price takers for the same services. While balance billing, OON billing, and private payment have been relatively intractable issues, surprise $\mathrm{OON}$ medical billing may be a solvable problem. ${ }^{[6]}$ Insurers have the opportunity to negotiate a fair payment rate on behalf of their members, so they are not surprised by unaffordable OON bills. Out-of-network charges are incurred when members visit providers who are not contracted with their insurer. The frequency of involuntary OON care is not inconsequential, especially when patients have constrained physician choice due to emergent problems or limited inhospital physician networks. ${ }^{[7]}$ Furthermore, a study from a large national insurer found that $22 \%$ of emergency patient visits at in-network hospitals resulted in a bill from a doctor who was not in the insurance company network. ${ }^{[8]}$ In such cases, the required payment amounts are typically very high and the primary responsibility of the member, rather than the insurer. The financial liability can be devastating to the patient, who is not afforded the opportunity to pay for the care received at rates similar to the reasonable payment amount negotiated by insurers or paid by Medicare and Medicaid.

Table 3. Taxonomy for price gouging

\begin{tabular}{ll}
\hline Term & Definition \\
\hline $\begin{array}{l}\text { Insured } \\
\text { Medical Billing }\end{array}$ & $\begin{array}{l}\text { Occurs when an insured patient inadvertently receives care from an out-of-network provider and is } \\
\text { subsequently billed for the service. }{ }^{[9]} \\
\text { Occurs when a provider sends the patient a bill for the difference between full charges and the amount } \\
\text { the patient's plan paid. Managed care plans and service plans generally prohibit contracted providers } \\
\text { from balance billing except for allowed copayments, coinsurance, and deductibles. }\end{array}$ \\
& $\begin{array}{l}\text { Distinct from surprise medical billing, out-of-network billing occurs when patients knowingly seek } \\
\text { services from an out-of-network provider. Depending on the type of plan, the cost of the service may be } \\
\text { partially covered by the plan, or it may be the full responsibility of the patient. }\end{array}$ \\
Out-of-Network Billing & $\begin{array}{l}\text { The patient is responsible for paying for their own care in full. Negotiation with the provider is } \\
\text { Sometimes possible but not guaranteed, especially in emergency situations. }\end{array}$ \\
Pninsured & Patients with high \\
Private Pay & $\begin{array}{l}\text { A hospital incurs bad debt when payment for services is not provided. This can happen when patients do } \\
\text { not apply for financial assistance or when patients are unwilling or unable to pay for the services they } \\
\text { received. }{ }^{[13]} \\
\text { Charity care is provided without the expectation of payment because the patient cannot pay for the } \\
\text { services they received, as defined by policy criteria. }{ }^{[13]}\end{array}$ \\
\hline
\end{tabular}


A number of technical distinctions and practices contribute to price gouging in healthcare. The various terms key to understanding price gouging by healthcare providers are listed in Table 3. Three terms each are defined for insured and uninsured patients and relates these terms to the payer source.

Four of the terms defined in Table 3 are potentially related to price gouging, while bad debt and charity care typically result in no payment. These four terms are discussed below.

\subsection{Surprise out-of-network medical billing (SMB)}

A surprise medical bill describes charges arising when an insured individual inadvertently receives care from an outof-network provider. ${ }^{[9]}$ Members typically confirm that the facility is in-network but are unaware that the providers they receive treatment from may not all be in-network. Doctors who treat the patient are not always employed by the facility and thus bill separately; this is especially common in emergency care ${ }^{[3]}$ One study found that approximately $8 \%$ of privately insured individuals used OON care and $40 \%$ of those claims involved surprise OON claims, most related to emergency care, ${ }^{[7]}$ and another found that $22 \%$ of emergency visits, which occurred at in-network facilities over $99 \%$ of the time, resulted in a bill from an OON physician. ${ }^{[8]}$ Further confusion arises when an insurance company confirms that a specific hospital is in-network, but does not highlight that physicians who may treat the patient could be OON. ${ }^{[3]}$

The average surprise OON emergency bill cost more than $\$ 900$, though there was a wide range; the highest was for more than $\$ 19,000 .^{[3]}$ The study also found wide variation across the country over the likelihood that someone would get a surprise medical bill. In McAllen, Tex., for example, the rates of surprise billing were $89 \%$, compared with Boulder, Colo., where it was near zero. ${ }^{[8]}$ This implies that surprise medical billing is a solvable problem. ${ }^{[6]}$ The practice of surprise medical billing is the most blatant example of the imperfect conditions in the dysfunctional medical market design, leading critics to conclude there is no such thing as a fixed price for a procedure or test, and the uninsured pay the highest prices of all. ${ }^{[14]}$

\subsection{Balance billing (BB)}

Balance billing occurs when providers do not accept payment from the insurer as payment in full and send a bill for the difference to the patient. Balance billing typically correlates with surprise OON bills; the insurer might pay the OON bill at a predetermined rate, but since the OON provider does not have a contract with the insurer, the provider is allowed to balance bill the patient. ${ }^{[9]}$ Some states have laws against select types of balance billing, but no federal protections exist to protect all patients. ${ }^{[10]}$ The Affordable Care Act (ACA) requires non-grandfathered health plans to provide the same level of cost sharing for in-network and OON emergency services, but patients can still be balance billed by OON providers. ${ }^{[9]}$ Medicare patients receive some level of protection from balance billing: non-participating providers cannot balance bill patients any more than $15 \%$ of the Medicare fee schedule for the service. ${ }^{[9]}$ Finally, the majority of managed care organization (MCO) provider contracts include a nobalance-billing clause: if a patient receives care in-network, they cannot be balance billed. ${ }^{[10]}$

\subsection{Out-of-network billing (OON)}

Out-of-network (OON) billing is distinct from surprise outof-network medical billing when the patient is aware that he or she is receiving care out-of-network. This may occur because the patient feels that a certain OON provider will provide better quality care than an in-network provider, the patient may have an established relationship with the OON provider, or the network might be inadequate. This latter issue can be a source of conflict between patients and payers due to its subjective nature. A patient may believe that they need a certain procedure or a specific type of specialist who is not available within a reasonable distance in-network. Patients may send an appeal to the payer for coverage of the OON service, but this is not always granted. ${ }^{[15]}$ Depending on the type of plan, some OON coverage may be offered, but the patient could also be liable for full charges. ${ }^{[11]}$

\subsection{Private pay (PP)}

A small number of patients may choose to pay entirely for their own care due to perceived improved quality and other factors. ${ }^{[16]}$ Additionally, as more patients enroll in high-deductible health plans, paying out of pocket is becoming more common. ${ }^{[17]}$ Private pay is the default option for the uninsured. The uninsured depend on continuing stable health, but when accidents and other emergencies occur, they must seek care or risk death or disability. ${ }^{[18]}$ These patients are sometimes granted charity care, but in many cases the provider expects them to pay in full. ${ }^{[19]}$ Private pay patients are typically expected to pay full charges as determined by the provider chargemaster ${ }^{[20]}$ rather than a measurable amount. Patients may be able to negotiate small discounts or payment plans, but the provider has no contractual obligation to provide these benefits and the patient has very little negotiation power. ${ }^{[21]}$ Private pay patients have more leverage if they seek to negotiate before receiving services: in fact, some patients have found that they can find better deals than they could even through insurance by paying in cash for their care. ${ }^{[22,23]}$ This trend has prompted the development of services to pair patients with doctors who are willing to negotiate cash payments for care. ${ }^{[17]}$ 


\subsection{Impact of price gouging to patients}

About one quarter of adults under 65 in the U.S. report that they or someone in their household had problems paying or an inability to pay medical bills in the past 12 months. ${ }^{[24]}$ This portion of the population includes not only the low income and uninsured, but also those with middle-class incomes and public or private insurance. ${ }^{[24,25]}$ Insured patients with high-deductible plans are more likely to have problems paying medical bills than insured patients with lower deductible plans, and enrollment in high-deductible employersponsored plans is growing. ${ }^{[26]}$ Additionally, out-of-pocket costs are growing for insured patients, largely driven by increases in deductible costs. ${ }^{[27-29]}$ Medical debt often occurs when providers engage in price-setting behavior, and especially surprise OON billing. Approximately $32 \%$ of insured patients who had difficulty paying their medical bills received care from an OON provider, and $69 \%$ of that group reported that they were unaware that the provider was out of network when they received the care. ${ }^{[24]}$ Surprise OON bills are particularly prevalent in emergency care. ${ }^{[9]}$ Medical bills can easily reach five figures and average to about $\$ 900 .{ }^{[8]}$ Still, even relatively small medical bills can have serious consequences: nearly half of Americans cannot afford an expected $\$ 400$ expense without selling assets or borrowing money. ${ }^{[8]}$ Unaffordable medical bills have wide-ranging consequences: patients sometimes draw upon long-term savings accounts such as retirement funds and college funds, and people who are having trouble paying medical bills are more likely to skip or delay care. ${ }^{[24]}$ Some patients are driven to declare bankruptcy: $11 \%$ of those with medical bill problems say they have declared bankruptcy at some point and that medical bills were at least a partial contributor to their bankruptcy. ${ }^{[24]}$ Over half of bankruptcies in the United States are associated with medical issues, and out-of-pocket medical costs are much higher for uninsured patients compared to the average for all medically bankrupt families. ${ }^{[30]}$ Some of the highest out-of-pocket expenses that contribute to medical bankruptcies come from injuries, which are frequently treated in the emergency department. ${ }^{[30]}$

In addition to a lack of patient negotiation power, other practices may contribute to price gouging, especially horizontal mergers, vertical mergers, and certificate of need regulations. Mergers have become increasingly common in the healthcare industry, giving providers greater license to charge unaffordable prices and less accountability for lower quality care. ${ }^{[23]}$

\section{RElationship BETWEEN CHARGES, COSTS, AND COST SHIFTING}

Price gouging trends can be examined by tracking costs, charges, and recovery rates over time. Figure 1 shows the

Published by Sciedu Press costs and charges per discharge for all payers from 20012014. There has been a substantial gap between prices and payments for healthcare services during the 15-year trend. Charges were 2.36 times higher than costs in 2001, rising to 3.82 times higher in 2014. This growing gap reflects a $178 \%$ increase in charges between 2001 and 2014 compared to a $72 \%$ increase in costs during the same period. Use and intensity have accounted for a lesser portion of the observed healthcare cost growth during these years compared to growing medical prices. ${ }^{[31,32]}$ The widening chasm between costs and charges and the resulting reduced recovery rates are also reflected specifically in Medicare inpatient payments.

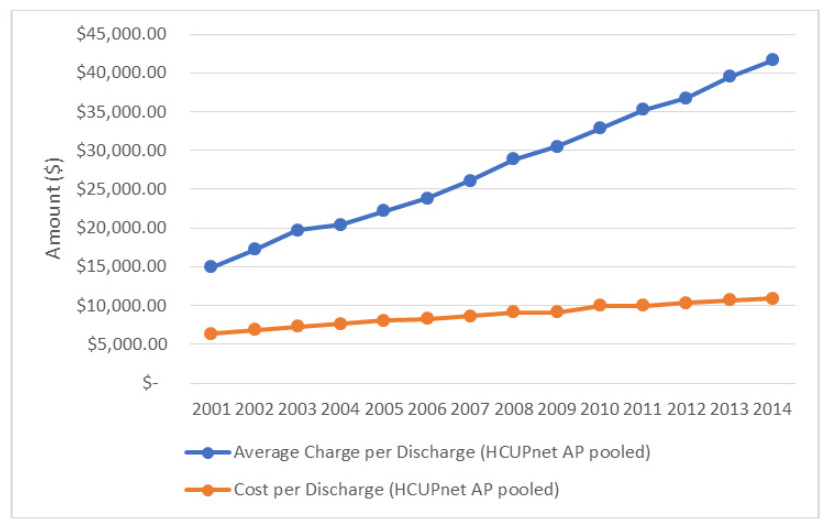

Figure 1. Hospital inpatient care charges and costs per discharge for all payers, 2001-2014 ${ }^{[33]}$

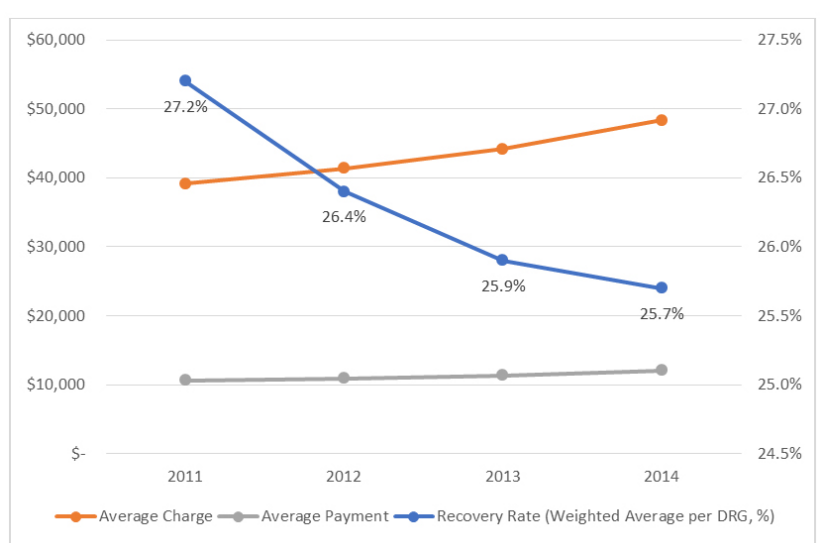

Figure 2. Medicare national hospital inpatient average charge, payment, and recovery rate for 2011-2014 ${ }^{[34]}$

Figure 2 illustrates a 4-year trend of the relationship between charges, payments, and recovery rates for Medicare inpatient discharges from the top 100 DRGs 2011-2014. The recovery rate (payments as a percentage of charges) has dropped from $27.2 \%$ to $25.7 \%$ during this time. This drop reflects primarily an increase in charges rather than a decrease in payment; the rate of charge increase has been greater than the rate of 
payment increase. Nevertheless, hospital profitability has increased during this same period.

Figure 3 illustrates a similar trend for physician recovery rates with payments as a percentage of charges for six specialties that are often associated with surprise medical bills and ranges from a high of $33.9 \%$ (ENT) to a low of $16.0 \%$ (Anesthesiology). The figure compares 2012 and 2014. The mean recovery rate for all physicians and other care suppliers in 2014 is $36.1 \%$. The average overall recovery rate for all physicians and other care suppliers dropped $2.5 \%$ (37.8\% to $36.1 \%$ ) from 2012 to 2014 with similar decreases in the six specialties shown in the figure. This suggests that either the charges are too high, the payments are too low, or both.

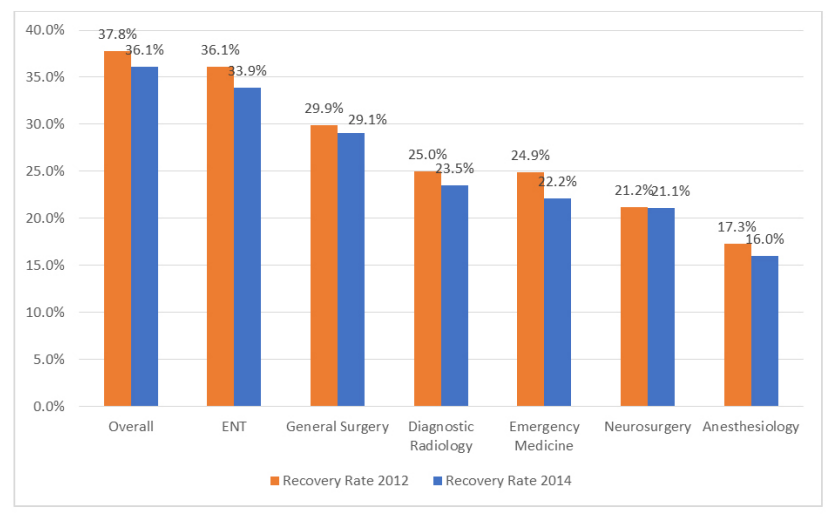

Figure 3. Medicare average physician charge recovery rate by specialty, 2012 and $2014^{[35,36]}$

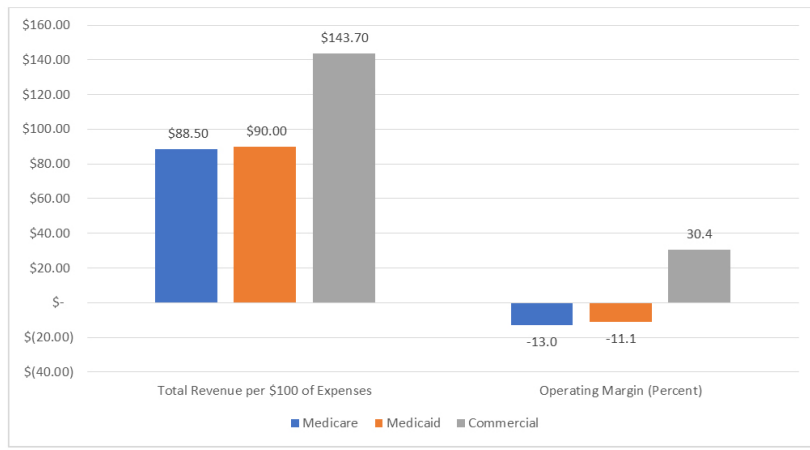

Figure 4. Relative hospital revenue, expenses, and margin by payer, $2014^{[40]}$

\subsection{Cost shifting}

Cost shifting has been a part of the healthcare system for decades and occurs when the cost of care for one patient is covered in part, or in whole, by another payment source. ${ }^{[37]}$ Another approach defines cost shifting as the difference between the actual payment and the payment amount that would have resulted in an equal margin by all payers. ${ }^{[19,38]}$ In a definitive study conducted for Americans' Health Insurance
Plans, the American Hospital Association, The Blue Cross Blue Shield Association, and Premera Blue Cross, it was found that Medicare and Medicaid cost shifted by $9.4 \%$ and $14.7 \%$, respectively, while commercial payers paid $23.1 \%$ above the full cost of care. ${ }^{[37]}$ A more recent analysis of cost shifting derived from a 2016 American Hospital Association survey in Figure 4 shows continued cost shifting by Medicare and Medicaid (13.0\% and $11.1 \%$, respectively) while commercial payers pay $30.4 \%$ above costs. ${ }^{[39]}$

The categorization of operating margins by payer in 2014 illustrates traunching by hospitals. The term traunch, as used in finance, commonly refers to a combination of related securities offered as part of the same capital structure transaction. The surplus by different payer source can be described as a form of traunching by providers. ${ }^{[39]}$ The surplus by payer source in Figure 4 reflects these distinct surplus traunches. Physicians are not required to report costs. However, similar payment traunches exist for physicians when compared to overall payment averages. Medicaid pays $40 \%$ below the average, Medicare pays $11 \%$ below the average, and commercial payers pay $14 \%$ above the average. ${ }^{[37]}$

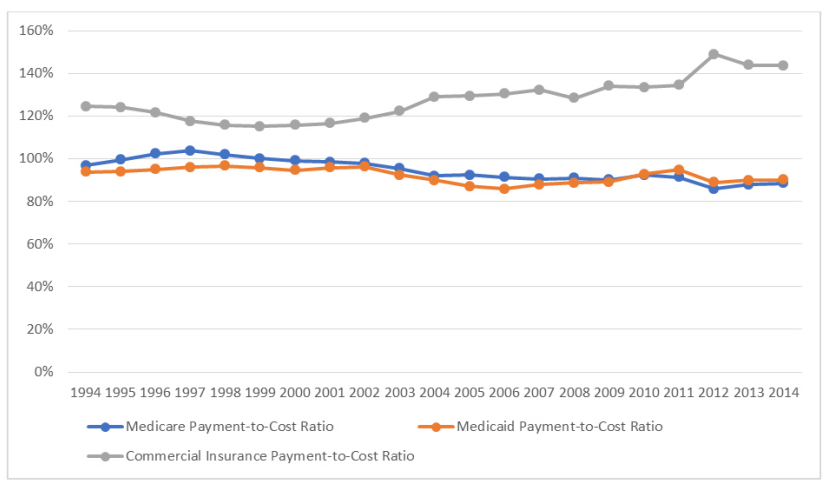

Figure 5. Payment-to-cost ratios for medicare, medicaid, and commercial insurance for hospitals 1994-2014 ${ }^{\text {[39] }}$

As discussed previously, Medicare and Medicaid cause providers to function as price takers which allows Medicare and Medicaid to pay providers below the cost of care. Figure 5 shows a 21-year trend of the payment-to-cost ratios for the three major payment categories to hospitals and reveals a number of important implications: first, Medicaid payments to hospitals have been lower than costs for the entire 21-year timeframe, while Medicare payments have been less than costs for all years except 1996-1999. However, commercial payers as a group have consistently paid more than the cost of care, ranging from $115.1 \%$ to $143.7 \%$ over the same period. The analysis suggests that commercial payers subject to price negotiations as well as patients subjected to price gouging emanating from price setting behavior provide the 
surplus to offset the underpayment by Medicare, Medicaid, and uncompensated care.

While hospitals are being paid below costs by Medicare and Medicaid, it is apparent that this loss is compensated by receiving higher payment amounts from commercial insurance and other sources. This is demonstrated by the positive and rising operating margin. Figure 6 shows a 21-year trend (1994-2014) for nearly 5,000 hospitals in the nation. While the overall average for hospital margin has been positive during the entire 21-year period, hospital operating margins have been growing steadily during the last 7 years. To the extent that overall hospital operating margins have been positive during the 21-year period, the combined impact of price setting, price negotiation, and price taking behavior with various payers in relation to the costs of care has been successfully managed by hospitals. However, despite the positive hospital industry operating margin for an extended period of time, a large number of hospitals experienced negative operating margins. Indeed, a substantial number of hospitals have a negative operating margin, ranging from approximately $19 \%$ of hospitals with negative operating margins to approximately $33 \%$ of hospitals with negative operating margins over the 21-year period. ${ }^{[41]}$

\section{Policy initiatives to ADdRess HEALTHCARE PRICE GOUGING}

Price gouging has evolved over many years in the healthcare system, with little systematic consideration by providers of the larger policy implications of this behavior. However, ignoring these implications has created repercussions at both the national and state level. In June 2019, both Congress and the Trump administration were actively pursuing measures to address healthcare provider billing practices. President Trump issued an Executive Order described as a significant step toward requiring hospital and insurer price transparency, ${ }^{[43]}$ while the United States Senate Health Committee approved a package of proposed reforms on SMB. ${ }^{[44]}$

Healthcare payment reform initiatives have also advanced at the state levels as well as within commercial insurers. A multiplicity of state legislative and regulatory efforts have been undertaken in an attempt to determine a fair payment rate for surprise OON bills, including: an arbitration process wherein the patient and provider agree on a fair payment for the services the patient received, ${ }^{[45]}$ a percentage of the Medicare payment for the service, ${ }^{[46]}$ and various formulas and benchmarks (such as the price in the FAIR health database $)^{[47]}$ combined to determine payment. ${ }^{[48]}$ Several states ban the practice of balance billing entirely. ${ }^{[49]}$ While nearly every state had at least one proposed bill related to

Published by Sciedu Press surprise OON billing just in 2016, only a small fraction of these bills passed. ${ }^{[50]}$

Some of the most notable legislation is in effect in New York, Texas, Colorado, and California. New York State policy allows patients who receive surprise OON bills to pay only the amount of their regular in-network cost-sharing and emergency-care patients are held harmless from OON surprise bills. An independent dispute resolution process is available for doctors. ${ }^{[29]}$ However, this regulation only relates to insurers, and does not included self-insured employer plans, which represent significant share of larger employers. ${ }^{[9]}$ Texas' legislation to mitigate price gouging went into effect in September of 2015. The bill allows consumers to participate in a mediation process through the Department of Insurance when they receive an OON bill exceeding $\$ 500$ from a radiologist, anesthesiologist, pathologist, emergency department physician, neonatologist, or an assistant surgeon who was based in an in-network facility. ${ }^{[3]}$ Patients must be clearly informed of this right by the physician when the bill is sent. This bill inspired several other similar bills, including one recently passed in Arizona. ${ }^{[51]}$ Colorado requires that contracted providers hold patients harmless and only collect coinsurance, deductibles, or copayments as specified in the patient's contract with their plan. ${ }^{[52]}$ Additionally, if the carrier's network is deemed to be adequate and the beneficiary knowingly receives OON care, the insurance provider is only required to pay the lesser of the provider's bill of charges, a negotiated rate, the greater of the HMO's average in-network rate for the relevant geographic area or the usual, customary, and reasonable rate for such geographic area. The beneficiary is not protected from balance billing. In California, patients who receive care at in-network facilities are required to pay only in-network cost sharing. This applies to non-emergency care since emergency physicians are already barred from balance billing via other legislation. ${ }^{[44]}$ However, this law does not apply to self-insured employer health plans. Health plans pay non-contracting physicians the plan's average contracted rate or $125 \%$ of the Medicare rate, whichever is greater. Doctors may appeal the payment amount through a binding dispute resolution process. ${ }^{\text {[4] }}$

Notably, each of these laws attempts to balance patient, provider, and payer interests. Lawmakers lift a significant financial burden from their communities with legislation to reduce or prevent surprise OON billing. Considering the prevalence of surprise OON billing, it is likely that legislation will continue to be proposed and enacted. Therefore, patients, providers, and payers should inform themselves on the issue so they can meaningfully contribute to the conversation. Future legislative solutions should include some flexibility so individual patients, providers, and payers can 
find a mutually agreeable solution, but future laws should also include a quantitative basis to ensure that patients will not be price gouged. Policy interventions can increase availability of cost information prior to using OON physician services, but they may be less helpful when patients have constrained physician choice due to emergent problems or limited in-hospital physician networks. ${ }^{[7]}$

\section{Conclusions}

Surprise OON billing is a prevalent practice in healthcare that reflects a disruptive discontinuity in the complex payment system to providers associated with significant financial hardship on the patient. However, attributing the cause of OON surprise billing to unconscionable hospitals and physicians $^{[20]}$ obscures the root cause which lies in a complex medical-legal-regulatory system that creates a vast disconnect between the point of care where patients are served and the final bill received by a patient, often several months after the care episode. In between these two focal points is a byzantine ${ }^{[53]}$ process based on: 1) a regulatory pricing system that requires uniform prices to all customers, yet allows discounts to the bulk of payers, 2) chargemasters that reflect little relationship to costs or reasonable payments, 3 ) a huge gap between charges and costs, which has evolved for decades and shows no indication of stabilizing or reversal, 4) a complex market structure that positions providers as price takers, price setters and price negotiators with those least able to afford care paying the largest profit segment of all payer categories, 5) an unbundling system that breaks down every supply and service used, and 6) a cost finding system required by Medicare that allocates exorbitant overhead costs to services.

This discussion suggests that most provider payments for care are not based on what is fair, rather they are based on what is negotiated with commercial payers, imposed by government payers, and price gouged for $\mathrm{OON}$ and uninsured payers. We suggest three recommendations to address surprise medical billing: 1) Create a fair payment formula to cover the full costs of care and a reasonable surplus for the provider, 2) conduct an internal review by providers to scrutinize the prevailing billing structure in the United States and more carefully understand the burden that it places on those most unable to afford, and 3) create an informed policy discussion at the state and national level to generate regulatory solutions. These solutions should involve key stakeholders including hospital and physician groups, health insurance associations, underwriters, employers and consumers.

\section{ACKnOWledgements}

This project was funded by Bright Health Plan, Minneapolis, Minnesota. The authors would like to acknowledge the contributions of Kate Kepple, the Marketing Director of the Bright Health Plan for her assistance in gathering and analyzing data.

\section{CONFLicts OF InTEREST Disclosure}

The authors declare they have no conflicts of interest.

\section{REFERENCES}

[1] Rosenthal E. An American sickness: How healthcare became big business and how you can take it back. New York: Penguin Press 2017. 416 p.

[2] Legal Dictionary. Price gouging. [updated 2016 Jan 14 cited 2019 May 26]. Available from: https://legaldictionary.net/pr ice-gouging/

[3] Sanger-Katz M, Abelson R. Surprise! insurance paid the E.R. but not the doctor. The New York Times. [updated 2016 Nov 16 cited 2019 May 3]. Available from: https ://nyti.ms/2f $1 \mathrm{P} 11 \mathrm{a}$

[4] Hacker JS. Why an open market won't repair American healthcare? The New York Times. [updated 2017 Apr 4; cited 2019 May 3]. Available from: https://www.nytimes.com/2017/04/04/books/revie w/an-american-sickness-elisabeth-rosenthal.html

[5] Brill S. America's bitter pill: Money, politics, backroom deals, and the fight to fix our broken healthcare system. New York: Random House; 2015. 528 p.

[6] Becker AL. Many emergency room patients could face 'surprise bills'. CT Mirror. [updated 2016, Nov 16 cited 2019 May 3]. Available from: https://ctmirror.org/2016/11/16/stud y-many-er-patients-seen-by-out-of-network-docs-c ould-face-higher-bills/

[7] Kyanko KA, Curry LA, Busch SH. Out-of-Network physicians: How prevalent are involuntary use and cost transparency? Health Serv Res. 2013; 48(3): 1154-1172. PMid: 23088523. https : //doi.org/10.1111/1475-6773.12007

[8] Cooper Z, Morton FS. Out-of-network emergency-physician bills an unwelcome surprise. N Engl J Med. 2016; 375(20): 1915. PMid: 27959612. https://doi.org/10.1056/NEJMp1608571

[9] Pollitz K. Surprise medical bills. The Henry J Kaiser Family Foundation. [updated 2016 Mar 17; cited June 29]. Available from: https://www.kff.org/private-insurance/issue-b rief/surprise-medical-bills/

[10] Kongstvedt PR. Health insurance and managed care: What they are and how they work. In: 4th ed. Burlington, Massachusetts: Jones \& Bartlett Learning; 2016. 294 p.

[11] Health insurance plan \& network types: HMOs, PPOs, and more HealthCare.gov Web site. [updated 2019; cited 2019 Jun 29]. Available from: https://www.healthcare.gov/choose-a-plan/ plan-types/ 
[12] High deductible health plan (HDHP). HealthCare.gov Web site. [updated 2019; cited 2019 Jun 29]. Available from: https : / www . he althcare.gov/glossary/high-deductible-health-plan/

[13] American Hospital Association. Uncompensated hospital care cost fact sheet. [updated 2016; cited 2019 May 30]. Available from: https://www . aha.org/factsheet/2017-01-01-uncompens ated-hospital-care-cost-fact-sheet-2016-update

[14] Rosenthal E. An American sickness: How healthcare became big business and how you can take it back. New York: Penguin Press; 2017. $416 \mathrm{p}$.

[15] Boodman E. An 'insurance warrior' fights to get pricey therapies covered. STAT News. [updated 2016 Apr 25 cited 2019 May 4]. Available from: https://www.statnews.com/2016/04/25/in surance-warrior/

[16] Hamilton MT. Shock your doctor: Ditch insurance and pay in cash. The Federalist. [updated 2016 Aug 2 cited 2019 May 4]. Available from: http://thefederalist.com/2016/08/02/sho ck-your-doctor-ditch-insurance-and-pay-in-cash/

[17] Kutscher B. Building bundles for self-pay patients. Modern Healthcare. [updated 2016 Apr 2 cited 2018 May 24]. Available from: http://www.modernhealthcare.com/article/20160 402/MAGAZINE/304029977

[18] Riffkin R. Cost still a barrier between Americans and medical care. Gallup. [updated 2014 Nov 28 cited 2018 May 4]. Available from: http://www.gallup.com/poll/179774/cost-barrier -americans-medical-care.aspx?version=print

[19] Coughlin TA, Holahan J, Caswell K, et al. Uncompensated care for the uninsured in 2013: A detailed examination. The Henry J Kaiser Family Foundation. [updated 2014 May 30 cited 2019 June 25]. Available from: https://www.kff.org/uninsured/report/u ncompensated-care-for-the-uninsured-in-2013-a-det ailed-examination/

[20] Nation GA, III. Obscene contracts: The doctrine of unconscionability and hospital billing of the uninsured. The Kentucky Law Journal. 2005; 94(1): 101.

[21] Carrns A. For uninsured, tips in seeking to reduce a medical bill. The New York Times. [updated 2012 Mar 14 cited 2019 May 3]. Available from: https: //bucks.blogs.nytimes.com/2012/03/14/for-uninsured -tips-in-seeking-to-reduce-a-medical-bill/?src=twr

[22] Beck M. How to cut your health-care bill: Pay cash. The Wall Street Journal. [updated 2016 Feb 16 cited 2019 May 11]. Available from: http://www.wsj.com/articles/how-to-cut-you r-health-care-bill-pay-cash- 1455592277

[23] Lankford K. Pay cash for your healthcare. Kiplinger. [updated 2015 Feb; cited 2019 May 4]. Available from: http://wWw.kiplinger.com/article/insurance/T027 -C000-S002-pay-cash-for-your-health-care.html

[24] Hamel L, Norton M, Pollitz K, et al. The burden of medical debt: Results from the kaiser family foundation/new york times medical bills survey. The Henry J Kaiser Family Foundation. [updated 2016 Jan 5 cited 2019 Jun 20]. Available from: https://www.kff.org/health-costs/report/the-burde n-of-medical-debt-results-from-the-kaiser-famil $\mathrm{y}$-foundationnew-york-times-medical-bills-survey/

[25] Blau M. In the state with the highest medical debt, it's the middle class who carries the burden. STAT News. [updated 2017 Mar 24 cited 2019 May 19]. Available from: https://www. statnews.com/2 017/03/24/mississippi-medical-debt-middle-class/

[26] American Hospital Association. Chartbook chart 1.22: distribution of employer-sponsored health insurance enrollment by type of plan, 1988-2015. Trendwatch Chartbook. [updated 2016 cited 2019 Jun
20]. Available from: https://www.aha.org/guidesreports/ 2016-05-10-chartbook-chart-122-distribution-emplo yer-sponsored-health-insurance-0

[27] Herrick DM, Frost A. Can consumers be smart health-care shoppers? The Wall Street Journal. [updated 2017 Apr 11 cited 2019 May 4] Available from: https://www.wsj.com/articles/can-consu mers-be-smart-health-care-shoppers-1491962640

[28] Claxton G, Rae M, Long M, et al. 2016 employer health benefits survey. The Henry J Kaiser Family Foundation. [updated 2016 Sep 14 cited 2019 Jun 1]. Available from: https://www.kff .org/health-costs/report/2016-emplo yer-health-benefits-survey/

[29] Claxton G, Rae M, Long M, et al. 2015 employer health benefits survey. The Henry J Kaiser Family Foundation. [updated 2015 Sep 22 cited 2019 Jun 1]. Available from: https://www.kff.org/health-costs/report/2015-emplo yer-health-benefits-survey/

[30] Himmelstein D. Medical bankruptcy in the united states, 2007: Results of a national study. Am J Med. 2009; 122(8): 742-746. PMid: 19501347. https://doi.org/10.1016/j.amjmed. 2009. 04.012

[31] Adler L. What is driving U.S. healthcare spending? America's unsustainable healthcare cost growth. Bipartisan Policy Center. [updated 2012 Sep 20 cited 2019 Jun 20]. Available from: https://bipartisanpolicy.org/report/what-driving-u s-health-care-spending-americas-unsustainable-hea lth-care-cost-growth/

[32] Robert Wood Johnson Foundation. What are the biggest drivers of cost in U.S. healthcare? [updated 2011 Jul 1 cited 2019 May 30]. Available from: https://www.rwjf.org/en/library/resear $\mathrm{ch} / 2011 / 07 /$ what-are-the-biggest-drivers-of-cost-i $\mathrm{n}$-u-s--health-care-.html

[33] Health Care Cost and Utilization Project. [updated 2018 May 16; cited 2019 Jun 1]. Available from: https://www.hcup-u s.ahrq.gov/news/exhibit_booth/hcupnet_brochure.jsp. Accessed June 28, 2019.

[34] Centers for Medicare \& Medicaid Services. Medicare Provider Utilization and Payment Data: Inpatient. [updated 2018 Aug 14 cited 2019 Aug 20]. Available from: https://www.cms . gov/Research-Statistics-Data-and-S ystems/Statistics-Trends-and-Reports/Medicare-Pro vider-Charge-Data/Inpatient.html

[35] Centers for Medicare and Medicaid Services. Medicare Physician and Other Supplier National Provider Identifier (NPI) Aggregate Report, Calendar Year 2014. [updated 2017 Oct 31 cited 2019 May 4]. Available from: https://data.cms.gov/Medicare-Physi cian-Supplier/Medicare-Physician-and-Other-Supplie r-National-Pro/4a3h-46r6

[36] Centers for Medicare and Medicaid Services. Medicare Provider Utilization and Payment Data: Physician and Other Supplier CY 2012. [updated 2017 Sep 22; cited 2019 May 4]. Available from: https://data.cms.gov/Medicare-Physician-Supplier/ Medicare-Provider-Utilization-and-Payment-Data-Phy /jzd2-pt4g. Accessed May 20, 2019.

[37] Frakt, AB. How much do hospitals cost shift? A review of the evidence. The Milbank quarterly. 2011; 89(1): 90-130. doi:10.1111/j.1468-0009.2011.00621. https://doi.or g/10.1111/j.1468-0009.2011.00621.x PMid:21418314 PMCid:PMC3160596

[38] Fox W, Pickering J. Hospital \& physician cost shift: Payment level comparison of Medicare, Medicaid, and commercial payers. Milliman. 2008. 
[39] American Hospital Association. Chartbook chart 4.6: aggregate hospital payment-to-cost ratios for private payers, Medicare, and Medicaid, 1994-2014. Trendwatch Chartbook 2016. [updated 2016; 2019 May 4]. Available from: https://www. aha.org/guidesre ports/2016-05-10-chartbook-chart-46-aggregate-hos pital-payment-cost-ratios-private-payers

[40] American Hospital Association. Trendwatch chartbook 2016: supplementary data table, trends in hospital financing. [updated 2016; cited 2019 Jun 29]. Available from: https://www . aha.org/system/files/research/reports/ tw/chartbook/2016/table4-4.pdf

[41] Tompkins CP, Altman SH, Eilat E. The precarious pricing system for hospital services. Health Affairs. 2006; 25(1): 45-56. PMid: 16403744. https://doi.org/10.1377/hlthaff.25.1.45

[42] American Hospital Association. Chartbook chart 4.2: aggregate total hospital margins and operating margins, 1994-2014. Trendwatch Chartbook 2016. [updated 2016; 2019 Aug 20]. Available from: https ://www . aha.org/guidesreports/2016-05-10-chart book-chart-42-aggregate-total-hospital-margins-and -operating-margins

[43] Luthi S. Trump's transparency executive order leaves details to HHS, CMS. Modern Healthcare. [updated 2019 Jun 24 cited 2019 Jun 29]. Available from: https://www . modernhealthcare.com/payment/trumps-t ransparency-executive-order-leaves-details-hhs-cms

[44] Luthi S. Senate health committee may change surprise billing proposals ahead of floor vote. Modern Healthcare. [updated 2019 Jun 26 cited 2019 Jun 29]. Available from: https://www.modernhealthcare.com/politics-policy/ senate-health-committee-may-change-surprise-billi ng-proposals-ahead-floor-vote
[45] Hancock K. Relating to consumer information concerning facilitybased physicians and notice and availability of mediation for balance billing by a facility-based physician. Texas Legislature. 2015; SB 481(84).

[46] Bonta R. Healthcare coverage: Out-of-network coverage. California Legislature. 2016; AB 72 (2015-2016).

[47] FAIR health consumer. [updated 2017; 2019 May 4]. Available from: https://fairhealthconsumer.org

[48] New York State Department of Financial Services. Protection from surprise bills and emergency services. New York State Department of Financial Services. [updated 2015 Mar 31 cited 2019 May 4]. Available from: http://www.dfs.ny.gov/consumer/hprotection. $\mathrm{htm}$

[49] Davidson L. Bill advances to stop 'surprise billing' for medical emergencies. The Salt Lake Tribune. [updated 2017 Feb 21 cited 2019 May 20]. Available from: http://www.sltrib.com/home/4968 335-155/bill-advances-to-stop-surprise-billing

[50] Cousart C. Answering the thousand-dollar debt question: An update on state legislative activity to address surprise balance billing. National Academy for State Health Policy. [updated 2016 Apr 11 cited 2019 May 20]. Available from: https://nashp.org/answering-the-thousand-dollar-d ebt-question-an-update-on-state-legislative-activ ity-to-address-surprise-balance-billing/

[51] Lesko D. Insurers; health providers; claims mediation. Arizona Legislature. 2017; SB 1441 (2016-2017).

[52] 10-16-705(3) and 10-16-704. Colorado Legislature.

[53] Mueller KP. Bamboozled: How a non-existent 'surgery' during ER visit cost \$30k. NJ.com. [updated 2017 Feb 13 cited 2019 May 20]. Available from: http: //www.nj.com/business/index.ssf/2017/02/bamboo zled_how_a_non-existent_surgery_during_er_vi.html 